\title{
The effects of extensive taste preexposure on the acquisition of conditioned taste aversions
}

\author{
ANTHONY L. RILEY, W. J. JACOBS, JR., and JOHN P. MASTROPAOLO \\ American University, Washington, D.C.
}

\begin{abstract}
Animals extensively exposed to water during rearing showed no evidence of a conditioned taste aversion to water following a single pairing of water and lithium chloride ( $\mathrm{LiCl})$, indicating that, with sufficient preexposure, conditioned taste aversions can be completely attenuated. Although showing no aversion following a single conditioning trial, the preexposed subjects completely avoided water when repeated water-LiCl pairings were given, indicating further that, on the initial conditioning trials, some association had been established between the taste and toxicosis but that it was too weak to affect behavior, in other words, was a silent association. With repeated conditioning trials, this weak association became sufficiently strong to suppress consumption. The data were discussed in terms of the effects of taste preexposure on the acquisition of conditioned taste aversions.
\end{abstract}

If consumption of a particular solution is followed by administration of a toxin, the rat will typically avoid consumption of that solution on a subsequent exposure (see Garcia \& Ervin, 1968, Revusky \& Garcia, 1970, and Rozin \& Kalat, 1971). Although rapidly and reliably acquired (Garcia, Kimeldorf, \& Koelling, 1955), such conditioned taste aversions can be weakened by a number of manipulations (see Riley \& Clarke, 1977). For example, if a rat is given exposure to a taste solution before that taste is paired with toxicosis, the subsequent aversion is considerably attenuated (Bauermeister \& Schaeffer, 1969; Elkins, 1973, 1974; Fenwick, Mikulka, \& Klein, 1975; Kalat, 1974; McLaurin, Farley, \& Scarborough, 1963; Nachman, 1970). In general, the strength of the acquired aversion is inversely related to the amount of preexposure; that is, as the number of preexposures increases, the strength of the conditioned aversion decreases (Bauermeister \& Schaeffer, 1969; Elkins, 1973).

Because each preexposure appears to effect a decrease in the amount of aversion acquired during subsequent conditioning, it is possible that, given extensive taste preexposure, no aversion would be acquired when conditioning is attempted. Although substantially reduced, aversions still occur when consumption of an extensively preexposed solution is followed by toxicosis (see Fenwick et al., 1975, and Nachman, 1970). For example, Nachman (1970) reported that rats reared with continuous access to water reduced consumption of water by approximately $38 \%$ following a single pairing

W. J. Jacobs is currently at the Department of Psychology, University of British Columbia, Vancouver, British Columbia V6T 1W5, Canada. Requests for reprints should be sent to Anthony L. Riley, Psychopharmacology Laboratory, Department of Psychology, American University, Washington, D.C. 20016. of water with lithium chloride ( $\mathrm{LiCl})$. Before we conclude that aversions are acquired despite extensive taste preexposure, however, several points should be noted with regard to the Fenwick et al. (1975) and Nachman (1970) reports. First, the maximum number of preexposures given by Fenwick et al. (1975) was 20. It is possible that, with greater preexposure, further attenuation might have occurred. This possibility would appear to be answered by Nachman (1970), who reared rats for 48 days with unlimited access to water. As described above, these extensively preexposed subjects still acquired taste aversions to water. Although aversions to the preexposed taste were acquired, it should be noted that, following the preexposure to water, these subjects were given 15 exposures to a novel solution over a 24-day period before familiar water was paired with toxicosis; that is, 24 days intervened between the taste preexposure and the conditioning phases of the experiment (Experiment 4, Nachman, 1970; see also Elkins, 1974). Because, as has been reported previously, the attenuating effects of taste preexposure are reduced as the period between preexposure and conditioning is increased (McLaurin et al., 1963; but see Kalat \& Rozin, 1973), it is possible that aversions would have been totally attenuated to the preexposed taste if conditioning had occurred immediately following taste preexposure. Therefore, whether or not aversions can be totally attenuated following extensive taste preexposure remains unclear.

In the following experiment, rats were reared with continuous access to a specific taste for 75 consecutive days. Immediately following the preexposure period, the rats were given a pairing of the preexposed taste and $\mathrm{LiCl}$. If, as described, each preexposure retards the acquisition of an aversion, then it might be expected that no aversion would be acquired following the pairing of the preexposed taste with toxicosis. 


\section{METHOD}

\section{Subjects}

The subjects were 12 experimentally naive, female rats of Long-Evans descent, approximately 75 days of age at the beginning of the experiment. The subjects were maintained on a 12-hlight/12-h-dark cycle (lights on at $0800 \mathrm{~h}$ ) and at an ambient temperature of $23^{\circ} \mathrm{C}$ for the duration of the experiment.

\section{Apparatus}

All subjects were individually housed in stainless steel, wiremesh cages. In the front of each cage were openings into which graduated Nalgene tubes were placed for presentations of water or saccharin $(0.1 \% \mathrm{w} / \mathrm{v}$ sodium saccharin, Fisher Purified).

\section{Procedure}

Phase 1: Taste preexposure. At birth, 12 rat pups were assigned randomly to one of two nursing mothers $(n=6$ for each mother). From birth until weaning, the pups in Group $F$ $(n=6)$ were given ad-lib access to tap water. The second group of pups, Group $N(n=6)$, was given ad-lib access to saccharin during this period. Upon being weaned (Day 24), the pups were separated from their mothers and were housed individually in wire-mesh cages for 40 days, during which time the subjects in Group F and Group N continued to receive ad-lib access to water and saccharin, respectively. Throughout both weaning and individual housing of the pups, the fluid reservoirs for each group were washed and were filled daily with the appropriate taste solution. Food was available ad lib during this taste-preexposure phase.

Phase 2: Conditioning. On Day 64, all subjects were deprived of fluids. On the next day (Day 65), they were given 20-min access to their respective solutions, that is, water (Group F) and saccharin (Group N). This procedure was repeated for 12 consecutive days, at which point all subjects were approaching and drinking from the tube within 2 sec of its presentation.

Following adaptation to this fluid-deprivation schedule, all subjects were given 20 -min access to water followed immediately by an intraperitoneal (ip) injection of $1.8 \mathrm{mEq}$., $0.15 \mathrm{M} \mathrm{LiCl}$. Because of the differential rearing conditions for the two groups of subjects, water was familiar for Group $\mathrm{F}$ and novel for Group $\mathrm{N}$. Following this treatment, Group $\mathrm{F}$ and Group $\mathrm{N}$ were given 20 -min access to saccharin for three consecutive post- $\mathrm{LiCl}$ recovery sessions.

This alternating procedure of conditioning/recovery was continued until all subjects had received eight complete cycles. On the day following the last post- $\mathrm{LiCl}$ recovery session, the subjects were given 20 -min access to water in a final one-bottle aversion test. No injections followed this test.

\section{RESULTS}

All determinations of statistical significance were made at $\mathrm{p}<.05$, two-tailed.

Over the 12 days of adaptation to restricted fluid access (Days 65.76), all subjects gradually increased their consumption, drinking an average of approximately $10 \mathrm{ml}$ on each of the final 3 days of adaptation. When novel water was presented to Group $\mathrm{N}$ on the first conditioning trial prior to $\mathrm{LiCl}$ treatment, there was a slight, but nonsignificant, decrease in consumption below the previous 3 days' saccharin baseline. There was no significant change in consumption by Group $F$, which received familiar water on this conditioning trial. During the post$\mathrm{LiCl}$ recovery sessions, there were no significant differences in saccharin consumption between Groups $\mathbf{N}$ and
$\mathrm{F}$, both groups drinking approximately $10 \mathrm{ml}$ on each of the recovery days.

On the second exposure to water, Group $\mathrm{N}$ significantly decreased consumption of water below the amount consumed on the first conditioning trial $[\mathrm{t}(5)=$ 11.01]. Group F, however, did not significantly decrease its water consumption on this exposure. Instead, these subjects showed a slight, but nonsignificant, increase in water consumption above the amount consumed on the first conditioning trial. On this test, Group $\mathrm{N}$ drank significantly less water than did Group F $[\mathrm{t}(10)=9.22]$.

Figure 1 presents the mean consumption of water for Groups $\mathrm{N}$ and $\mathrm{F}$ over repeated conditioning trials and on the final aversion test. As illustrated, with repeated conditioning, the rats in Group $\mathrm{N}$ continued to decrease their consumption of water, each drinking less than $0.5 \mathrm{ml}$ of water by the fourth conditioning trial. On the other hand, over the first five conditioning trials, the subjects in Group F did not drink significantly less water than they did before the water- $\mathrm{LiCl}$ pairings. By the sixth conditioning trial, these subjects significantly decreased water consumption $[t(5)=3.36]$. With repeated conditioning trials, they continued to decrease consumption, each drinking less than $0.5 \mathrm{ml}$ of water on the final aversion test. By the eighth conditioning trial, there were no significant differences between Groups $\mathrm{N}$ and $\mathrm{F}$ in the amount of water consumed.

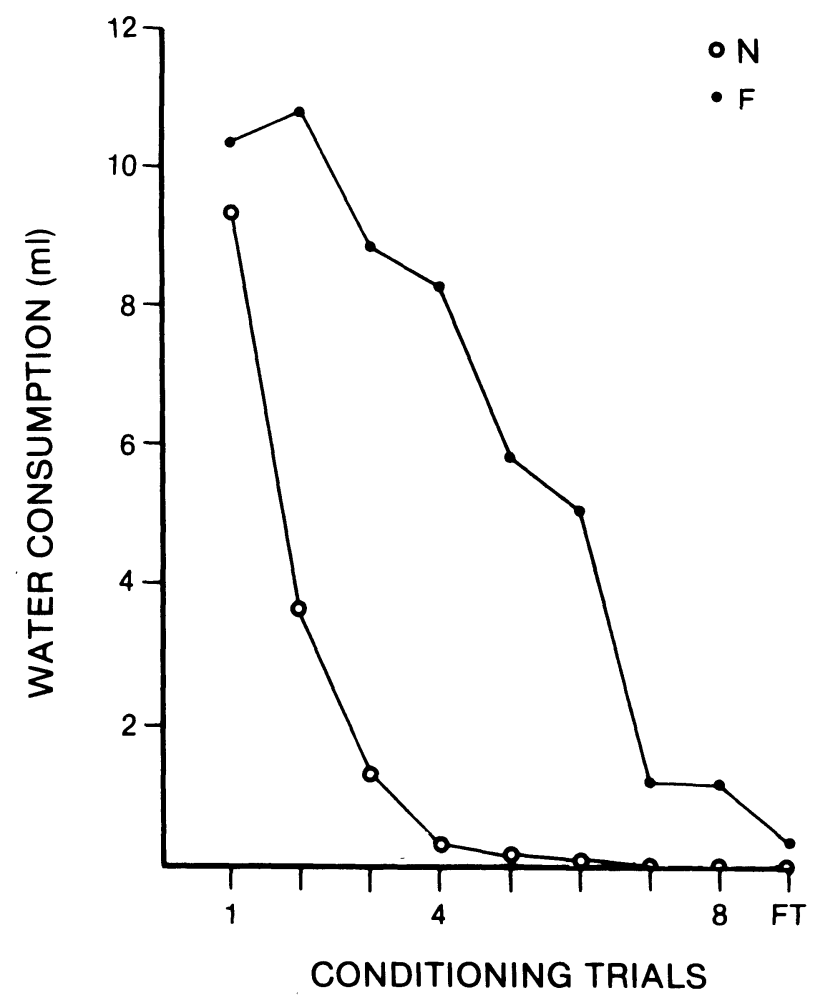

Figure 1. Mean water consumption (in milliliters) for Groups $F$ and $\mathbf{N}$ over repeated conditioning trials and on the final aversion test (FT). 


\section{DISCUSSION}

As illustrated, animals extensively exposed to a taste prior to conditioned taste aversion training showed no evidence of an aversion following a single conditioning trial. Although these results are consistent with the finding that taste preexposure attenuates the acquisition of conditioned aversions (Elkins, 1973; Fenwick et al., 1975), they are not consistent with the earlier demonstration that rats given extensive taste preexposure still acquired an aversion following only a single conditioning trial (Nachman, 1970). The acquisition of aversions in the Nachman (1970) report, however, may have been due to the fact that 24 days separated the preexposure and conditioning phases of the experiment (see also Elkins, 1974). As noted earlier, McLaurin et al. (1963) reported that with intervals as short as 3 days separating taste preexposure and conditioning, the effects of taste preexposure are diminished.

Several points should be noted with regard to the failure of preexposed subjects in the present experiment to acquire a taste aversion following the initial pairings of the familiar taste with $\mathrm{LiCl}$. First, the absence of an aversion is not a function of the specific solution used, that is, water. In two related studies, we have found that subjects reared with access to either saccharin or sodium chloride also initially failed to display an aversion to the familiar solution. Second, in the present experiment, the absence of an aversion was demonstrated by the failure of preexposed subjects to decrease consumption of water following its pairing with $\mathrm{LiCl}$. It could be argued that a between-groups analysis may be more appropriate in detecting aversions in these preexposed subjects, that is, that subjects poisoned following consumption of water may have consumed less than control subjects injected with physiological saline. However, as described, the poisoned subjects did not significantly change their consumption of water following its pairing with $\mathrm{LiCl}$. In order to see a difference between poisoned and nonpoisoned groups, therefore, subjects treated with physiological saline would have to increase consumption of water on a second exposure. Although rats given an injection of physiological saline following consumption of a novel solution often increase consumption of that solution on a second exposure, this increase is due to the fact that the animal's consumption of the solution is reduced on the first exposure, a decrease reflecting the rat's neophobic response to a novel solution (see Mitchell, 1976). Given that the subjects in the present experiment had stabilized consumption of familiar water over preexposures, there is no reason to assume that consumption would significantly increase following a control injection.

Although preexposed subjects did not acquire an aversion to water following a single conditioning trial, aversions were conditioned with repeated pairings of the familiar taste and toxicosis, a finding in agreement with earlier work by Elkins (1974), who demonstrated that complete aversions could be conditioned to familiar solutions if repeated conditioning trials were given. That in the present study aversions were eventually acquired to a solution to which no aversions had been initially evident suggests that preexposed subjects did form an association between the taste and toxicosis during the initial conditioning trials, but that the association was too weak to be displayed in behavior, that is, was a behaviorally silent association (Weisman \& Dodd, 1979). Repeatedly pairing the taste and toxicosis presumably strengthened the association to a level sufficient to suppress consumption (see also Kulkosky, Sickel, \& Riley, 1980, Pilcher, Stolerman, \& D'Mello, 1978, and Riley, Jacobs, \& LoLordo, 1976). The existence of such silent associations is consistent with other work in conditioned taste aversions in which associations have been formed but have not been evident in behavior (see Riccio \& Haroutunian, 1977). For example, rats often show no suppression of consumption in the presence of environmental cues paired with toxicosis (Dacanay \& Riley, 1982). However, these same cues can block (see Kamin, 1969) the acquisition of conditioned aversions to a novel taste when taste aversion training is attempted in the presence of these cues (Batson \& Best, 1979;
Cappell \& Poulos, 1979; Dacanay \& Riley, 1982), suggesting that an association had been established between the environmental cues and toxicosis (Archer, Sjoden, Nilsson, \& Carter, 1979; Berk \& Miller, 1978).

In summary, the present experiment demonstrates that extensive taste preexposure can totally attenuate the one-trial acquisition of conditioned taste aversions. Although initially attenuated, taste aversions can be acquired with repeated conditioning trials to a degree similar to that induced in nonpreexposed subjects.

\section{REFERENCES}

Archer, T., Suoden, P., Nilsson, L., \& Carter, N. Role of exteroceptive background context in taste-aversion conditioning and extinction. Animal Learning \& Behavior, 1979, 7, 17-22.

BAtson, J., \& BEST, P. Drug-preexposure effects in flavoraversion learning: Associative interference by conditioned environmental stimuli. Journal of Experimental Psychology: Animal Behavior Processes, 1979, 5, 273-283.

Bauermeister, J., \& Schaeffer, R. Relations between preconditioned rate of solution ingestion and rate of post-irradiation intake. Physiology \& Behavior, 1969, 4, 1019-1021.

BerK, A., \& Miller, R. LiCl-induced aversions to audiovisual cues as a function of response measure and CS-US interval. Behavioral Biology, 1978, 24, 185-208.

Cappell, H., \& Poulos, C. Associative factors in drug pretreatment effects on gustatory conditioning: Cross-drug effects. Psychopharmacology, 1979, 64, 209-213.

Dacanay, R., \& RILEY, A. The UCS preexposure effect in taste aversion learning: Tolerance and blocking are drug specific. $A n$ imal Learning \& Behavior, 1982, 10, 91-96.

Elkins, R. Attenuation of drug-induced bait-shyness to a palatable solution as an increasing function of its availability prior to conditioning. Behavioral Biology, 1973, 9, 221-226.

Elkins, R. Conditioned flavor aversions to familiar tap water in rats: An adjustment with implications for aversion therapy treatment of alcoholism and obesity. Journal of Abnormal Psycho$\log y, 1974,83,411-417$.

Fenwick, S., ,Mikulka, P., \& KLein, S. The effect of different levels of preexposure to sucrose on the acquisition and extinction of a conditioned aversion. Behavioral Biology, 1975, 14, 231-235.

Garcia, J., \& Ervin, F. Gustatory-visceral and telereceptorcutaneous conditioning: Adaptation in internal and external milieus. Communications in Behavioral Biology, 1968, 1, 389-415.

Garcia, J., Kimeldorf, D., \& Koelling, R. Conditioned aversion to saccharine resulting from exposure to gamma radiation. Science, 1955, 122, 157-158.

KalAT, J. Taste salience depends upon novelty, not concentration, in taste aversion learning in the rat. Journal of Comparative and Physiological Psychology, 1974, 86, 47-50.

Kalat, J., \& Rozin, P. "Learned safety" as a mechanism in long-delay taste-aversion learning in the rat. Journal of Comparative and Physiological Psychology, 1973, 83, 198-207.

KAmin, L. Predictability, surprise, attention and conditioning. In B. Campbell \& R. Church (Eds.), Punishment and aversive behavior. New York: Academic Press, 1969.

Kulkosky, P., Sickel, J., \& Riley, A. Total avoidance of saccharin consumption by rats after repeatedly paired injections of ethanol or LiCl. Pharmacology, Biochemistry \& Behavior, $1980,13,77-80$.

Mclaurin, W., Farley, J., \& Scarborough, B. Inhibitory effect of a preirradiation saccharin habituation on conditioned avoidance behavior. Radiation Research, 1963, 18, 473-478.

Mitchell, D. Experiments on neophobia in wild and laboratory rats: A reevaluation. Journal of Comparative and Physiological Psychology, 1976, 90, 190-197.

Nachman, M. Learned taste and temperature aversions due to 
lithium chloride sickness after temporal delays. Journal of Comparative and Physiological Psychology, 1970, 73, 22-30.

Pilcher, C., Stolerman, I., \& D'Mello, G. Aversive effects of narcotic antagonists in rats. In J. VanRee \& L. Terenius (Eds.), Characteristics and function of opioids. Amsterdam: Elsevier \& North-Holland, 1978.

REvUSKY, S., \& GarCiA, J. Learned associations over long delays. In G. Bower \& J. Spence (Eds.), Psychology of learning and motivation: Advances in research and theory (Vol. 4). New York: Academic Press, 1970.

Riccio, D., \& Haroutunian, V. Failure to learn in a taste aversion paradigm: Associative or performance deficit? Bulletin of the Psychonomic Society, 1977, 10, 219-222.

Riley, A., \& Clarke, C. Conditioned taste aversions: A bibliography. In L. Baker, M. Best, \& M. Domjan (Eds.), Learning mechanisms in food selection. Waco, Tex: Baylor University Press, 1977.

Riley, A., Jacobs, W., \& LoLondo, V. Drug exposure and the acquisition and retention of a conditioned taste aversion. Journal of Comparative and Physiological Psychology, 1976, 90, 799-807.

Rozin, P., \& Kalat, J. Specific hungers and poison avoidance as adaptive specializations of learning. Psychological Review, $1971,78,459-486$.

Weisman, R., \& DodD, P. The study of association: Methodology and basic phenomena. In A. Dickenson \& R. Boakes (Eds.), Mechanisms of learning and motivation: A memorial volume to Jerzy Konorski. Hillsdale, N.J: Erlbaum, 1979.

(Manuscript received for publication April 3, 1983.) 